TOLEDO, Cláudia Mansini Queda; JÚNIOR, Luiz Carlos de Souza. Análise dos apontamentos críticos ao judicial review. Revista Eletrônica Direito e Política, Programa de Pós-Graduação Stricto Sensu em Ciência Jurídica da UNIVALI, Itajaí, v.11, n.3, 30 quadrimestre de 2016. Disponível em: www.univali.br/direitoepolitica - ISSN 1980-7791.

\title{
ANÁLISE DOS APONTAMENTOS CRÍTICOS AO JUDICIAL REVIEW
}

\author{
ANALYSIS OF CRITICAL POINTS TO JUDICIAL REVIEW
}

Cláudia Mansini Queda Toledo ${ }^{1}$

Luiz Carlos de Souza Junior ${ }^{2}$

\begin{abstract}
SUMÁRIO: Introdução; 1. Aspectos mais relevantes dos marcos históricos que deram origem ao sistema do judicial review; 2. A dificuldade contramajoritária: a controvertida legitimidade dos juízes devido à sua origem não democrática; 3 . A supremacia judicial: objeção ao monopólio da suprema corte a respeito da interpretação final e vinculante da constituição; 4. Avaliação do status autônomo do direito; Considerações finais; Referências das fontes citadas.
\end{abstract}

\section{RESUMO}

O presente artigo objetiva analisar algumas críticas apresentadas na contemporaneidade a respeito do judicial review. Partindo de uma breve revisão do contexto embrionário estadunidense do fim do século XVIII e início do século XIX e fixando o olhar no fenômeno atual da ascensão institucional do Poder Judiciário, por meio do método analítico, bem como através de pesquisa bibliográfica e revisão teórica de artigos científicos, o estudo passará pela análise das críticas diretas ao judicial review, especificamente, as objeções relativas à dificuldade contramajoritária e à supremacia judicial. Com isso, após a exposição de breve avaliação do status autônomo do Direito, o resultado conclusivo da presente pesquisa conduz para o apontamento de que as objeções ao judicial review são apresentadas no intuito de defender a legitimidade democrática de órgãos eleitos da atuação dos graus de ativismo judicial e tomamos os

\footnotetext{
${ }^{1}$ Doutora em Direito Constitucional pela ITE-Bauru e Mestre em Direito das Relações Sociais pela PUC-SP. Especialista em Educação à Distância SENAC-Curitiba-PR. Professora de Direito Constitucional e Direitos Humanos na graduação em Direito da Faculdade de Direito do Sul de Minas, Pouso Alegre, MG. e de Horizontalização dos Direitos Fundamentais no curso de Mestrado da mesma instituição. Advogada. E-mail: quedatoledo@uol.com.br

${ }^{2}$ Mestrando em Constitucionalismo e Democracia pela Faculdade de Direito do Sul de Minas, Pouso Alegre, MG. Graduado em Direito pelo Centro Universitário Salesiano de São Paulo, U.E. Lorena. Graduado em Filosofia pela Universidade de Franca e especialista em Filosofia pela Faculdade Internacional Signorelli do Rio de Janeiro. Professor de Direito do Idoso, Antropologia e História do Direito, Psicologia Jurídica, Projeto Integrador I (Empreendedorismo, Liderança, Criatividade e Inovação) e Projeto Integrador II (Responsabilidade Social, Educação, Étnico-racial) na graduação em Direito da Universidade Vale do Rio Verde (UninCor, unidade de Três Corações e Caxambu, MG).E-mail: luizjuniorsdb@hotmail.com
} 
TOLEDO, Cláudia Mansini Queda; JÚNIOR, Luiz Carlos de Souza. Análise dos apontamentos críticos ao judicial review. Revista Eletrônica Direito e Política, Programa de Pós-Graduação Stricto Sensu em Ciência Jurídica da UNIVALI, Itajaí, v.11, n.3, 30 quadrimestre de 2016. Disponível em: www.univali.br/direitoepolitica - ISSN 1980-7791.

posicionamentos críticos elencados como uma tentativa de encarar o direito como autônomo, livre da politização do Judiciário e adequado à vontade popular por meio de seus representantes, não obstante, se deve levar em linha de conta que, na realidade, esta autonomia é relativa, uma vez que o Direito é submetido a influências externas ao seu campo (forças econômicas, políticas, religiosas, jornalísticas etc.), sendo que estas devem ser consideradas a partir das relações de força da sociedade.

Palavras-Chave: Judicial Review. Apontamentos críticos. Dificuldade Contramajoritária. Supremacia Judicial.

\section{ABSTRACT}

This article aims to analyze some criticism presented in contemporary regarding judicial review, based on a brief review of the US embryonic context of the late eighteenth and early nineteenth century and fixing his gaze on the current phenomenon of the rise of institutional judiciary. Through the analytical method, as well as through literature and theoretical review of scientific articles, the study will include the analysis of direct criticism of the judicial review, specifically, the objections regarding the Counter-Majoritarian difficulty and judicial supremacy. By the way, after exposure assessment of the autonomous status of law, the conclusive results of this research lead to the appointment of the objections to judicial review are presented in order to uphold the democratic legitimacy of elected bodies of the activities of degrees of judicial activism and take the listed critical positions in an attempt to face the law as autonomous, free from judicial politicization and adequate to the popular will through their representatives, however, one must take into account that, in reality, this autonomy is relative, since the law is subjected to external influences to its field (economic forces, political, religious, journalistic etc.), and these must be considered from the power relations of society.

Keywords: Judicial Review. Critical points. Counter-Majoritarian Difficulty. Judicial Supremacy.

\section{INTRODUÇÃO}

Trata-se neste artigo a respeito dos apontamentos críticos desenvolvidos por parcela da doutrina no âmbito constitucional que decaem sobre o controle de constitucionalidade herdado do modelo norte-americano, com o objetivo de analisar algumas críticas apresentadas na contemporaneidade a respeito do judicial review. Portanto, se realiza tais análises e, por conseguinte, tecem-se 
TOLEDO, Cláudia Mansini Queda; JÚNIOR, Luiz Carlos de Souza. Análise dos apontamentos críticos ao judicial review. Revista Eletrônica Direito e Política, Programa de Pós-Graduação Stricto Sensu em Ciência Jurídica da UNIVALI, Itajaí, v.11, n.3, $3^{\circ}$ quadrimestre de 2016. Disponível em: www.univali.br/direitoepolitica - ISSN 1980-7791.

seus pontos nevrálgicos para melhor se atribuir o sentido que as mesmas produzem num Estado Democrático de Direito.

Tal intuito se justifica pela atualidade do tema, uma vez que, pelo cenário político nacional hodierno, não só os meios acadêmicos, mas também a grande mídia vêm tratando a respeito da "politização do Judiciário" ou "judicialização da política", que reporta ao debate da elevação do intérprete/julgador em prejuízo do legislador ou vice-versa, encontrando relação entre direito e política que, no atual contexto, pode se caracterizar em uma certa ascensão institucional do Judiciário ao decidir sobre questões políticas, morais ou sociais.

No primeiro capítulo traçam-se as linhas gerais no tocante ao marco histórico da revisão judicial reconhecido pelos estudos que versam sobre controle de constitucionalidade: a decisão de John Marshall no caso Marbury versus Madison prolatada por influência do ensaio número 78 na obra "O Federalista" (The Federalist), de Alexander Hamilton.

Em seguida, discorre-se sobre a dificuldade contramajoritária enfrentada pelos magistrados que não foram eleitos por voto popular para compor a Corte Suprema e que, mesmo assim, são agasalhados pelo poder de invalidar normas aprovadas pelos representantes do povo democraticamente eleitos.

Passa-se então ao estudo da segunda objeção ao judicial review: a supremacia judicial, em que é questionada a primazia do tribunal constitucional na interpretação final e vinculante das normas constitucionais, em detrimento do posicionamento do Poder Legislativo ou popular.

Por fim, posteriormente a exposição de breve avaliação do status autônomo do Direito, são tecidas considerações finais que apontam para uma suficiência de elementos para se concluir que as objeções ao judicial review são apresentadas com o propósito de defender a legitimidade democrática de órgãos eleitos da atuação dos graus de ativismo judicial, bem como posicionamos as críticas elencadas como uma forma de assinalar o status autônomo do direito, livre da politização do Judiciário, adequado à vontade popular por meio de seus representantes etc., mas que isso nem sempre é possível, uma vez que, 
TOLEDO, Cláudia Mansini Queda; JÚNIOR, Luiz Carlos de Souza. Análise dos apontamentos críticos ao judicial review. Revista Eletrônica Direito e Política, Programa de Pós-Graduação Stricto Sensu em Ciência Jurídica da UNIVALI, Itajaí, v.11, n.3, $3^{\circ}$ quadrimestre de 2016. Disponível em: www.univali.br/direitoepolitica - ISSN 1980-7791.

efetivamente, a autonomia referida não pode ser analisada como absoluta, mas sim relativa, ao passo que o Direito está sob influência de outros campos (forças econômicas, políticas, religiosas, jornalísticas etc.) que devem ser considerados a partir das relações de força da sociedade.

\section{ASPECTOS MAIS RELEVANTES DOS MARCOS HISTÓRICOS QUE DERAM ORIGEM AO SISTEMA DO JUDICIAL REVIEW}

No desenvolvimento da maioria dos estudos que versam sobre controle de constitucionalidade encontram-se alguns marcos históricos importantes. Por isso, antes de adentrar nas linhas críticas relativas ao judical review, se faz mister a apresentação das origens da revisão judicial, perpassando pelo paradigmático caso Marbury versus Madison e pelo ensaio número 78 da obra "O Federalista" (The Federalist), de Alexander Hamilton, chegando até à influencia recebida pelo Brasil recém convertido em República que, outrossim, passa a adotar o argumento de que a Constituição é soberana e que os atos e leis que a contrariam são nulos.

Visando a sobreposição ao poder absolutista, além da separação de poderes, o modelo liberal clássico propôs uma declaração de direitos individuais em documento escrito ${ }^{3}$. Neste sentido, as Constituições escritas e rígidas dos Estados Unidos da América do Norte em 1787 influenciaram vigorosamente a história do Constitucionalismo, bem como a ideia da fiscalização da Constituição exercida pelo Judiciário, sobretudo a partir do controle de constitucionalidade das leis, por via de exceção, ocorrido inicialmente através da decisão prolatada pelo Chief Justice John Marshall no caso Marbury versus Madison, ao sustentar a tese da supremacia da lei constitucional sobre a lei ordinária.

Dessa forma, a concepção estadunidense de ordem constitucional aplicada ao caso Marbury versus Madison, muito embora não houvesse determinação

3 MENDES, Gilmar Ferreira; COELHO, Inocêncio Mártires; BRANCO, Paulo Gustavo. Curso de Direito Constitucional. São Paulo: Saraiva, 2007, p. 39. 
TOLEDO, Cláudia Mansini Queda; JÚNIOR, Luiz Carlos de Souza. Análise dos apontamentos críticos ao judicial review. Revista Eletrônica Direito e Política, Programa de Pós-Graduação Stricto Sensu em Ciência Jurídica da UNIVALI, Itajaí, v.11, n.3, 30 quadrimestre de 2016. Disponível em: www.univali.br/direitoepolitica - ISSN 1980-7791.

expressa do controle de constitucionalidade, conferiu o status de superioridade ao texto constitucional ${ }^{4}$.

Em linhas gerais, o caso Marbury versus Madison teve seu início em 1800, seguindo a narrativa de Woodrow Wilson ${ }^{5}$, a partir da tentativa de reeleição do federalista, então presidente dos Estados Unidos, John Adans, o qual nomeou seus correligionários para diversos cargos públicos, inclusive os vitalícios do Poder Judiciário, incluindo seu Secretário de Estado, John Marshall para a Suprema Corte e, ainda, para Juiz de Paz no Condado de Washington, Distrito de Columbia, nomeou William Marbury.

No entanto, este último não foi empossado antes do término do mandato de Adans. Assim, por determinação do novo presidente, Thomas Jefferson, seu Secretário de Estado, James Madison, não entregou o título de juiz de paz a Marbury.

Diante de tal negativa, dotado de inconformismo, Marbury requisitou ao Tribunal a notificação de Madison a fim que este apresentasse suas razões por meio das quais lhe negava o título de nomeação para possibilitar-lhe a posse. Não obtendo resposta, Marbury impetrou o writ of mandamus de forma direta à Corte Suprema6.

A Suprema Corte, diante da complexidade do caso, manteve-se inerte e, por isso, sendo atacada pela imprensa e pelo Congresso, pairando rumores de possibilidade de impeachment dos magistrados.

Até que depois de dois anos John Marshal (Presidente da Suprema Corte, então secretário de Justiça de Adams nomeado por ele como Presidente deste Tribunal) declarou o direito de Marbury à posse ao cargo almejado. E, desta

\footnotetext{
${ }^{4}$ LIJPHART, Arend. Modelos de democracia: desempenho e padrões de governo em 36 países. Rio de Janeiro: Civilização Brasileira, 2003, p. 254.

5 WILSON, Woodrow. Governo Constitucional dos Estados Unidos. Tradução Jacy Monteiro. São Paulo: Ibrasa, 1963, p. 47.

${ }^{6}$ SWISHER, Carl Brent. Decisões históricas da Corte Suprema. Rio de Janeiro: Forense, 1962, p.98.
} 
TOLEDO, Cláudia Mansini Queda; JÚNIOR, Luiz Carlos de Souza. Análise dos apontamentos críticos ao judicial review. Revista Eletrônica Direito e Política, Programa de Pós-Graduação Stricto Sensu em Ciência Jurídica da UNIVALI, Itajaí, v.11, n.3, $3^{\circ}$ quadrimestre de 2016. Disponível em: www.univali.br/direitoepolitica - ISSN 1980-7791.

forma, houve a consolidação jurisprudencial do judicial review, sendo que os Federalistas eram em maior número no Poder Judiciário.

Em sua decisão, Marshall problematizou a questão, dentre outras indagações, apresentando a interrogativa se a Suprema Corte era competente para julgar o caso. Sendo que, exatamente ao fundamentar esta questão, foi que o Chief Justice fixou as bases do judicial review, pois negou a incompetência da Corte Suprema para julgar o case, assim, declarou inconstitucional a lei federal que ampliava a competência da Suprema Corte, tornando nulo o ato do Congresso que objetivava ampliar as competências daquela Corte.

O fato é que a decisão de Marshall encontrou inspiração na doutrina de Alexander Hamilton, no clássico "O Federalista" ("The Federalist", no n. 78), escrito quinze anos antes do caso (Marbury versus Madison), haja vista que o referido autor já sustentava que:

A função de todos os juízes é a de interpretar as leis, a fim de aplicá-las aos casos concretos de vez em vez submetidos a seu julgamento; uma das regras mais óbvias da interpretação das leis é aquela segundo a qual, quando duas disposições legislativas estejam em contraste entre si, o juiz deve aplicar a prevalente; tratando-se de disposições de igual força normativa, a prevalente será indicada pelos usuais, tradicionais critérios 'lex posterior derogat legi priori','lex specialis derogat legi generali'; mas, evidentemente, estes critérios não valem mais, e valem ao contrário, em seu lugar, o óbvio critério 'lex superior derogat legi inferiori'- quando o contraste seja entre disposições de diversa força normativa: a norma constitucional, quando a Constituição seja 'rígida' e não 'flexível', prevalece sempre sobre a norma ordinária contrastante ${ }^{7}$.

\footnotetext{
7 HAMILTON, Alexander, JAY, John, MADISON, James. O Federalista (Um comentário à Constituição americana). Tradução por Reggy Zacconi de Moraes. Rio de Janeiro, Ed. Nacional de Direito. Apud ALMEIDA NETO, Manuel Carlos. Antecedentes históricos do controle difuso de constitucionalidade das leis. Disponível em http://www.buscalegis.ufsc.br/revistas/files/anexos/31795-36810-1-PB.pdf. Acesso em 3 de fevereiro de 2016 , p. 4.
} 
TOLEDO, Cláudia Mansini Queda; JÚNIOR, Luiz Carlos de Souza. Análise dos apontamentos críticos ao judicial review. Revista Eletrônica Direito e Política, Programa de Pós-Graduação Stricto Sensu em Ciência Jurídica da UNIVALI, Itajaí, v.11, n.3, 30 quadrimestre de 2016. Disponível em: www.univali.br/direitoepolitica - ISSN 1980-7791.

Mais tarde tal decisão se fez soar no Brasil recém convertido em República, o qual inspirou-se neste sistema: "Os autores de nossa Constituição, em cujo nome tenho algum direito de falar [...] eram discípulos de Madison e Hamilton" ${ }^{8}$.

Por isso, por força do Decreto $n^{\circ}$ 848, de 11 de outubro de 1890, foi expressamente previsto a possibilidade do Poder Judiciário declarar a inconstitucionalidade de uma lei. Havendo precisão de competência do Supremo Tribunal Federal para o julgamento de recursos das sentenças definitivas "quando a validade de uma lei ou acto de qualquer Estado seja posta em questão como contrario á Constituição, aos tratados e ás leis federaes e a decisão tenha sido em favor da validade da lei ou acto" ${ }^{\prime 9}$ (Decreto $n^{\circ} 848$, de 11 de outubro de 1890, art. $9^{\circ}$, parágrafo único, b).

Traçadas as linhas introdutórias do mecanismo de correção judicial em tela, passamos a discorrer diretamente sobre as objeções ao judicial review.

\section{A DIFICULDADE CONTRAMAJORITÁRIA: A CONTROVERTIDA LEGITIMIDADE DOS JUÍZES DEVIDO À SUA ORIGEM NÃO DEMOCRÁTICA}

Esta teoria está ligada às críticas apresentadas por Alexander M. Bickel, identificada em sua obra "The Least Dangerous Branch"10, ao tratar de "The Counter-Majoritarian Difficulty" nos seguintes termos:

The root difficult is that judicial review is a countermajoritarian force in our system. There are various ways of sliding over this ineluctable reality. (...)

An abstraction obscuring the reality that when the Supreme Court declares unconstitutional a legislative act or the action of an elected executive, it thwarts the will of representatives

\footnotetext{
${ }^{8}$ BARBOSA, Rui. Atos inconstitucionais. $3^{a}$ ed.. Campinas: Russel Editores, 2010, p. 30.

9 BRASIL. Decreto $n^{\circ} 848$, de 11 de outubro de 1890 , art. 9º parágrafo único, b. Disponível em http://www.planalto.gov.br/ccivil_03/decreto/1851-1899/d848.htm. Acesso em 5 de fevereiro de 2016. Tal dispositivo diz respeito à organização da Justiça Federal.

10 BICKEL, Alexander. The Least Dangerous Branch. New Haven: Yale University Press, 1963, pp. 16-17. Disponível em http://www.law.uh.edu/faculty/eberman/conlaw/Bickel.pdf. Acesso em 5 de fevereiro de 2016.
} 
TOLEDO, Cláudia Mansini Queda; JÚNIOR, Luiz Carlos de Souza. Análise dos apontamentos críticos ao judicial review. Revista Eletrônica Direito e Política, Programa de Pós-Graduação Stricto Sensu em Ciência Jurídica da UNIVALI, Itajaí, v.11, n.3, 30 quadrimestre de 2016. Disponível em: www.univali.br/direitoepolitica - ISSN 1980-7791.

of the actual people of the here and now; it exercises control, not in behalf of the prevailing majority, but against $\mathrm{it}^{11}$.

Os autores que, assim como Bickel, sustentam tal dificuldade defendem a inadmissibilidade de órgãos não eleitos e, em tese, menos responsáveis politicamente, como os órgãos do Poder Judiciário, invalidarem leis ou atos normativos oriundos do Poder Legislativo composto por representantes eleitos em uma democracia.

Diante disso, Michael Rosenfeld ${ }^{12}$ salienta que a objeção contramajoritária não está presente em todos os casos, haja vista que a jurisdição constitucional possui um componente técnico-jurídico e outro político.

O primeiro caso está ligado à aplicação do direito vigente de forma objetiva ao caso concreto, conforme ocorre nos casos em que a Corte Suprema declara a inconstitucionalidade de lei estadual que viola previsão constitucional relativa às Competências do Congresso Nacional. Neste sentido, é nítida a conclusão de que diante a edição de lei contrária ao dispositivo constitucional, esta será declarada inconstitucional e anulada, haja vista que se assemelha a declaração de inconstitucionalidade à prática da subsunção.

Frente ao segundo caso é que reside a dificuldade contramajoritária, pois o mesmo é decorrente do conteúdo aberto de diversas normas constitucionais, pois o conteúdo não pode ser definido de forma objetiva, tendo o intérprete/julgador que debruçar-se sobre o caso de forma subjetiva. Neste sentido, a legitimidade dos juízes frente à adoção de tal posicionamento é controvertida devido à sua origem não democrática, pois "quando se declara a inconstitucionalidade de uma

\footnotetext{
${ }^{11}$ Como base, e de difícil entendimento, é que a revisão judicial é uma força contramajoritária em nosso sistema. Existem várias maneiras de análise sobre esta realidade inquestionável. [...] Uma compreensão obscurecendo a realidade de que quando a Suprema Corte declara inconstitucional um ato legislativo ou a ação de um executivo eleito que frustre a vontade de representantes do povo reais do 'aqui e agora'; ele exerce controle, não em nome da maioria, mas contra ela" (tradução nossa).

12 ROSENFELD, Michael. Constitutional Adjudication in Europe and United States: paradoxes and contrasts. In: International Journal of Constitutional Law. Oxford University Press and New York University Shool of Law 2004, I-CON, Volume 2, Number 4, 2004, pp. 633-668. Disponível em http://icon.oxfordjournals.org/content/2/4/633.full. pdf + html?sid=6422b01f-be38-43dcbd51-72fbd5ba2edb. Acesso em 05 de fevereiro de 2016.
} 
TOLEDO, Cláudia Mansini Queda; JÚNIOR, Luiz Carlos de Souza. Análise dos apontamentos críticos ao judicial review. Revista Eletrônica Direito e Política, Programa de Pós-Graduação Stricto Sensu em Ciência Jurídica da UNIVALI, Itajaí, v.11, n.3, $3^{\circ}$ quadrimestre de 2016. Disponível em: www.univali.br/direitoepolitica - ISSN 1980-7791.

lei produzida no Legislativo, há, de certo modo, a frustração da vontade das pessoas que elegeram um Parlamento" ${ }^{13}$.

Por óbvio, ao depender da posição político ideológica na qual está imersa a jurisdição exercida pela Corte Suprema, o pêndulo tende a voltar-se para o entendimento do grupo de maior representatividade durante determinada época, seja ele de perfil progressista ou preservacionista.

Com isso, o próprio Waldron alerta que, nos Estados Unidos, os liberais colocavam em prática a revisão judicial como uma carta coringa opondo-se aos conservadores que se posicionavam contrários aos direitos que os tribunais liberais confirmavam"14. Neste sentido, Ran V. Hirschl em seus escritos "Towards juristocracy: the origins and consequences of the new constitutionalism", depois de análises direcionadas às experiências canadense, neozelandesa, israelense e sul-africana, afirma que a elevação do poder judicial pelo canal da constitucionalização é:

um pacto estratégico entre três partes: as elites políticas hegemônicas (e crescentemente ameaçadas) que pretendem proteger suas preferências políticas contra as vicissitudes da política democrática; as elites econômicas que comungam da crença no livre mercado e da antipatia em relação ao governo; e Cortes Supremas que buscam fortalecer seu poder simbólico e sua posição institucional" ${ }^{15}$.

Seguindo esta linha de raciocínio, podemos detectar a ilegitimidade política do modelo do judicial review no que tange aos valores democráticos, uma vez que dar privilégio para uma maioria de votos pertencentes ao menor número de magistrados não eleitos pelo povo e não responsabilizáveis iria acarretar na

13 OLIVEIRA, Leandro Correa de. O Judicial Review permite um diálogo entre poderes. Consultor Jurídico, 23 de novembro de 2012. Disponível em http://www.conjur.com.br/2012-nov23/leandro-oliveira-judicial-review-permite-dialogo-entre-poderes. Acesso 06 de fevereiro de 2016.

14 WALDRON, Jeremy. A essência da oposição ao judicial review. In: BIGONHA, Antônio Carlos Alpino; MOREIRA, Luiz (Org.). Legitimidade da jurisdição constitucional. Rio de Janeiro: Lumen Juris, 2010, p. 36.

15 HIRSCHL, Ran. Towards juristocracy: the origins and consequences of the new constitutionalism. Cambridge: Harvard University Press, 2004, p. 2014. Apud BARROSO, Luis Roberto. Constituição, Democracia e Supremacia Judicial: Direito e Política no Brasil Contemporâneo. Revista da Faculdade de Direito - UERJ, v. 2, n. 21, jan./jun. 2012. Disponível em http://www.epublicacoes.uerj.br/index.php/rfduerj/article/view/1794. Acesso em 7 de fevereiro de 2015, p.11. 
TOLEDO, Cláudia Mansini Queda; JÚNIOR, Luiz Carlos de Souza. Análise dos apontamentos críticos ao judicial review. Revista Eletrônica Direito e Política, Programa de Pós-Graduação Stricto Sensu em Ciência Jurídica da UNIVALI, Itajaí, v.11, n.3, 30 quadrimestre de 2016. Disponível em: www.univali.br/direitoepolitica - ISSN 1980-7791.

privação de direitos aos cidadãos comuns e afastaria prezados princípios de igualdade e representação política na deliberação derradeira de questões de direitos ${ }^{16}$.

Não obstante, embora tal crítica não tenha deixado de existir, encontra maior eco a compreensão que, se tratando da proteção a direitos fundamentais, principalmente das minorias, se justifica a decisão de um órgão não político.

Passamos na próxima parte deste trabalho à segunda crítica ao judicial review.

\section{A SUPREMACIA JUDICIAL: OBJEÇÃO AO MONOPÓLIO DA SUPREMA CORTE A RESPEITO DA INTERPRETAÇÃO FINAL E VINCULANTE DA CONSTITUIÇÃO}

Este elemento crítico parte do pressuposto de que a Suprema Corte é o ponto máximo da interpretação constitucional, pois há a primazia do tribunal constitucional na interpretação final e vinculante das normas constitucionais. Nos Estados Unidos esta corrente de pensamento intitula-se "constitucionalismo popular"17.

O primeiro teórico que podemos citar que se posiciona criticamente com relação à Supremacia Judicial, é Stephen Griffin, que chega a afirmar que o formato tomado pela revisão judicial no século XX não existia no contexto de Marbury versus Madison, portanto, quando o Judiciário protegia certos direitos do cidadão no início do século XIX o fazia em um tempo em que faltava ao país a proteção aos direitos civis, pois ainda não havia a dita democracy of rights. Tendo o movimento pelos direitos civis nos Estados Unidos criado uma democracia de

\footnotetext{
16 WALDRON, Jeremy. A essência da oposição ao judicial review. In: BIGONHA, Antônio Carlos Alpino; MOREIRA, Luiz (Org.). Legitimidade da jurisdição constitucional. Rio de Janeiro: Lumen Juris, 2010, p. 98.

17 BARROSO, Luis Roberto. Constituição, Democracia e Supremacia Judicial: Direito e Política no Brasil Contemporâneo. Revista da Faculdade de Direito - UERJ, v. 2, n. 21, jan./jun. 2012. Disponível em http://www.e-publicacoes.uerj.br/index.php/rfduerj/article/view/1794. Acesso em 7 de fevereiro de 2015, p. 11.
} 
TOLEDO, Cláudia Mansini Queda; JÚNIOR, Luiz Carlos de Souza. Análise dos apontamentos críticos ao judicial review. Revista Eletrônica Direito e Política, Programa de Pós-Graduação Stricto Sensu em Ciência Jurídica da UNIVALI, Itajaí, v.11, n.3, 30 quadrimestre de 2016. Disponível em: www.univali.br/direitoepolitica - ISSN 1980-7791.

direitos ${ }^{18}$, assim, todas as áreas do poder estatal começaram a se articular para efetivar os direitos constitucionais.

Outros poderes políticos começam a se interessar pela proteção de direitos e a preocupar-se com a formação de blocos de magistrados que mantenham uma linha ideológica parecida com a deles, assim o processo de politização das indicações dos juízes federais passam a ocorrer (com auge na era Reagan) ${ }^{19}$ e, com isso, corre-se o risco do surgimento da politização dos tribunais, o que acarretaria em julgados motivados por aspectos passionais e partidários não alicerçados pela objetividade e rigorosidade racional.

Para Stephen Griffin ${ }^{20}$ é o Legislativo quem possui maior abertura para as manifestações populares e o Judiciário, sem extirpar o controle do contexto jurídico do país, deve agir diante das matérias de julgamento, quando abarcar os litigantes tão somente.

18 Neste sentido, "o judicial review é exercido em uma 'democracia de direitos', cujas características seriam as seguintes: (1) direitos legais constitucionais e individuais são importantes e úteis para todos; (2) todos os três poderes têm sucesso em maior ou menor medida na aplicação e promoção de direitos; e (3) o Poder Judiciário ainda é ponto-chave para o estabelecimento de marcos interpretativos para a agenda de direitos". OLIVEIRA, Leandro Correa de. 0 Judicial Review permite um diálogo entre poderes. Consultor Jurídico, 23 de novembro de 2012. Disponível em http://www.conjur.com.br/2012-nov-23/leandro-oliveira-judicial-reviewpermite-dialogo-entre-poderes. Acesso 06 de fevereiro de 2016.

19 GRIFFIN, Stephen M.. The Age of Marbury: Judicial Review in a Democracy of Rights. Social Science Research Network. Tulane Law School Working Paper No. 2003-01. September 3, 2003. Disponível em http://papers.ssrn.com/sol3/papers.cfm?abstract_id=441240. Acesso em $27 \mathrm{de}$ fevereiro de 2016, p. 42.

20 GRIFFIN, Stephen M.. The Age of Marbury: Judicial Review in a Democracy of Rights. Social Science Research Network. Tulane Law School Working Paper No. 2003-01. September 3, 2003. Disponível em http://papers.ssrn.com/sol3/papers.cfm?abstract_id=441240. Acesso em 27 de fevereiro de 2016, p. 43. 
TOLEDO, Cláudia Mansini Queda; JÚNIOR, Luiz Carlos de Souza. Análise dos apontamentos críticos ao judicial review. Revista Eletrônica Direito e Política, Programa de Pós-Graduação Stricto Sensu em Ciência Jurídica da UNIVALI, Itajaí, v.11, n.3, 30 quadrimestre de 2016. Disponível em: www.univali.br/direitoepolitica - ISSN 1980-7791.

Dentro deste terceiro momento da abordagem, uma obra de referência que contribui para os escritos que ora se apresentam é Democracy and Distrust - $A$ Theory of Judicial Review (Democracia e Desconfiança - Uma Teoria do Controle Judicial de Constitucionalidade ${ }^{21}$, do jurista norte-americano John Hart Ely, se trata de fonte clássica a considerar nesta exposição.

No entendimento de John Hart Ely as Cortes Supremas teriam o condão de manter o controle tão somente dos procedimentos de produção de decisão, sendo impossibilitadas de julgar a respeito das escolhas institucionais.

A concepção de Ely é de que a intervenção judicial não deve prosperar diante das exigências democráticas que indicam que a produção de decisões tem o dever de emanar da sociedade ou daqueles que a esta representa legitimamente (soberania popular exercida por meio do sufrágio universal).

Dessa forma, para o referido jurista, as matérias controvertidas presentes no âmago social têm de ser resolvidas valorizando as regras da maioria em se tratando do contexto de democracias contemporâneas, ficando claro, assim, o viés procedimentalista do autor, alicerçada na compreensão democrática de que "a função do tribunal constitucional é a de proteger os sistemas de direito que possibilitam a autonomia privada e pública dos cidadãos"22 e de que o mister da Magna Carta "é determinar procedimentos políticos segundo os quais, os cidadãos, assumindo seu direito de autodeterminação, possam perseguir cooperativamente o projeto de produzir condições justas de vida"23.

21 ELY, John Hart. Democracia e Desconfiança - Uma teoria do controle judicial de constitucionalidade, Tradução de Juliana Lemos. São Paulo: Martins Fontes, 2010.

22 OLIVEIRA, Rafael Machado de. Ativismo judicial no Brasil e a importância da experiência norteamericana em hermenêutica constitucional. Fórvm Nacional da Advocacia Pública Federal. Disponível em http://www.advocaciapublica.com.br/forum/artigos/ativismo-judicial-no-brasil-ea-importancia-da-experiencia-norte-americana-em-hermeneutica-constitucional. Acesso em 15 de setembro de 2016.

23 OLIVEIRA, Rafael Machado de. Ativismo judicial no Brasil e a importância da experiência norteamericana em hermenêutica constitucional. Fórvm Nacional da Advocacia Pública Federal. Disponível em http://www.advocaciapublica.com.br/forum/artigos/ativismo-judicial-no-brasil-ea-importancia-da-experiencia-norte-americana-em-hermeneutica-constitucional. Acesso em 15 de setembro de 2016. 
TOLEDO, Cláudia Mansini Queda; JÚNIOR, Luiz Carlos de Souza. Análise dos apontamentos críticos ao judicial review. Revista Eletrônica Direito e Política, Programa de Pós-Graduação Stricto Sensu em Ciência Jurídica da UNIVALI, Itajaí, v.11, n.3, 30 quadrimestre de 2016. Disponível em: www.univali.br/direitoepolitica - ISSN 1980-7791.

No entanto, surge a indagação: e no caso de ausência de Parlamento satisfatoriamente democrático? Nesta situação, para o autor em tela, não se deve fortalecer o Judiciário para que este se sobreponha aos parlamentares considerando os magistrados detentores de capacidade ímpar no que tange à interpretação do sentimento popular, de modo diverso, é preciso robustecer a democracia do Parlamento e a Corte Constitucional encarregar-se de apurar se o processo legislativo afiançou a escuta das perspectivas diversas e se houve limitação dos direitos das minorias e, nessa situação, sob qual fundamento ${ }^{24}$.

Como é de se notar, John Hart Ely se posiciona como crítico do ativismo judicial, uma vez que sua teoria não permite a inserção de interpretações criativas.

Outro teórico que se faz presente na esteira dos críticos à Supremacia Judicial é Mark Tushnet ${ }^{25}$. Este faz diferenciação entre "Constituição grossa" (thick Constitution) e "Constituição fina" (thin Constitution). A primeira está relacionada aos dispositivos ligados à organização do governo, não menos importante, mas que não atrai a atenção da população e, consequentemente, não provoca debate ou querela popular. A "Constituição fina", por outro lado, seria objeto de interpretação dos meios populares, pois contem garantias fundamentais (como a igualdade e a liberdade) dispostas na Declaração da Independência e no Preâmbulo da Constituição.

Assim sendo, a questão levantada pelo referido teórico é justamente sobre a capacidade institucional ou, em outros termos, qual é habilidade que se tem fora dos tribunais federais para realizar a interpretação constitucional, mormente, no âmbito do Congresso Nacional? O autor norte americano, ressalvando o fato de parlamentares não possuírem a mesma formação e treinamento dos juízes ${ }^{26}$,

${ }^{24}$ Neste sentido, Ely menciona as "classificações suspeitas", que se tratam daquelas que devem ser alcançadas pelo controle judicial de constitucionalidade quando, verbi gratia, uma lei categorize as pessoas de acordo com a raça e prejudique de alguma forma certa minoria. ELY, John Hart. Democracia e Desconfiança - Uma Teoria do Controle Judicial de Constitucionalidade. Tradução de Juliana Lemos. São Paulo: Martins Fontes, 2010, p. 195 ss.

25 PINTO, José Guilherme Bernan Corrêa. Repercussão Geral e Writ of Certiorari. Dissertação (Mestrado em Direito). Rio de Janeiro: PUC-Rio, Departamento de Direito, 2006, p. 55. Disponível em http://www.dominiopublico.gov.br/download/teste/arqs/cp077202.pdf. Acesso em 06 de fevereiro de 2106.

26 Neste diapasão, entretanto, Barroso alerta que, embora os magistrados tenham treinamento próprio e o exercício do cargo pressuponha aptidão, os "temas envolvendo aspectos técnicos ou 
TOLEDO, Cláudia Mansini Queda; JÚNIOR, Luiz Carlos de Souza. Análise dos apontamentos críticos ao judicial review. Revista Eletrônica Direito e Política, Programa de Pós-Graduação Stricto Sensu em Ciência Jurídica da UNIVALI, Itajaí, v.11, n.3, 30 quadrimestre de 2016. Disponível em: www.univali.br/direitoepolitica - ISSN 1980-7791.

ressalta que é possível tais representantes políticos promoverem os valores constitucionais, mesmo sem a força da forma jurídica.

Outrossim, Mark Tushnet argumenta que os liberais têm receio em permitir que a população decida questões controversas, uma vez que optam por deixar a decisão nas mãos da Suprema Corte, ao invés de procurar arrimo no seio das camadas populares através da aprovação de leis ou emendas constitucionais ${ }^{27}$.

Rastreando em torno dos argumentos contrários à primazia judicial, no intuito de limitar a amplitude e profundidade das decisões judiciais e obter consenso em uma sociedade plural, podemos destacar ainda o pensamento de Cass Sustein ${ }^{28}$, que trás a baila a teoria minimalista, por meio da qual sustenta que as decisões judiciais devem agir estreitamente, ou seja, não adentrando em questões constitucionais de alta complexidade ou sem posicionar-se diante de questões moralmente controvertidas, as quais devem ser solucionadas por instâncias deliberativas (deliberação democrática).

A revisão judicial deveria ocorrer tão somente quando o Judiciário estivesse diante de um erro grave do Poder Legislativo. "O argumento fundamental do autor é que certas formas de ativismo judicial propiciam o 'refluxo', inspirando articulação de forças políticas contrárias ao sentido da decisão"29, deslegitimando a si própria.

científicos de grande complexidade podem não ter no juiz de direito o árbitro mais qualificado, por falta de informação ou de conhecimento específico". Trazendo, assim, o questionamento se o Poder Judiciário seria o mais eficiente na decisão em determinada matéria. BARROSO, Luis Roberto. Constituição, Democracia e Supremacia Judicial: Direito e Política no Brasil Contemporâneo. Revista da Faculdade de Direito - UERJ, v. 2, n. 21, jan./jun. 2012, p. 12. Disponível em http://www.e-publicacoes.uerj.br/index.php/rfduerj/article/view/1794. Acesso em 7 de fevereiro de 2015.

27 Apud PINTO, José Guilherme Bernan Corrêa. Repercussão Geral e Writ of Certiorari. Dissertação (Mestrado em Direito). Rio de Janeiro: PUC-Rio, Departamento de Direito, 2006, p. 64.

28 SUSTEIN, Cass R.. Beyond Judicial Minimalism. The Law Scholl The University of Chicago. September 2008. 25 pp. Disponível em http://www.law.uchicago.edu/files/files/LE432.pdf. Acesso em 27 de fevereiro de 2016.

29 BUNCHAFT, Maria Eugenia. Minimalismo Judicial, Constitucionalismo Democrático: uma reflexão sobre os direitos de minorias sexuais da Jurisprudência da Suprema Corte Norte-Americana. Revista Novos Estudos Jurídicos, vol. 19, n. 1, 2014, Universidade do Vale do Itajaí. Disponível em http://siaiap32.univali.br/seer/index.php/nej/article/view/5545. Acesso em 27 de fevereiro de 2016. p. 128. 
TOLEDO, Cláudia Mansini Queda; JÚNIOR, Luiz Carlos de Souza. Análise dos apontamentos críticos ao judicial review. Revista Eletrônica Direito e Política, Programa de Pós-Graduação Stricto Sensu em Ciência Jurídica da UNIVALI, Itajaí, v.11, n.3, 30 quadrimestre de 2016. Disponível em: www.univali.br/direitoepolitica - ISSN 1980-7791.

Existem outros autores que apresentam críticas à Supremacia Judicial frente ao tema da revisão judicial, no entanto, como o interesse não é de esgotar as fontes das quais emanam tais posicionamentos, passamos a traçar breve avaliação a respeito do status autônomo do Direito e, em seguida, as considerações finais que se fazem necessárias.

\section{AVALIAÇÃo DO STATUS AUTÔNOMO DO DIREITO}

É perceptível que as críticas elencadas almejam anotar o status autônomo do Direito, livre da politização do Judiciário, adequado à vontade popular por meio de seus representantes etc., porém, será isto sempre possível, uma vez que o Direito está sob influência de outros campos (forças econômicas, políticas, religiosas, jornalísticas etc.)?

A sustentação a respeito da autonomia relativa do direito significa levar em conta que o discurso jurídico e as decisões jurídicas estão atrelados à dimensão do poder, por isso se diz sobre relações de força da sociedade, isto a partir de uma postura crítico-reflexiva baseada na sociologia do século XX que identifica a faceta ideológica do Direito.

Para maior explicitação de elementos teóricos de suficiência ou não desta tendência identificada, há de se considerar, por exemplo, a compreensão sociológica da teoria do campo jurídico de Pierre Bourdieu ${ }^{30}$, o qual considera as práticas e os discursos jurídicos como resultados do funcionamento de um campo cuja lógica própria está estabelecida não só pelas regras escritas (que, sem dúvida, reduz a variabilidade comportamental), mas pelas condutas dos agentes jurídicos que se sujeitam mais ou menos estritamente às imposições da legislação, notando-se ainda uma parcela de arbitrário, imputável a variações organizacionais como "a composição do grupo de decisão ou os atributos dos que estão sujeitos a uma jurisdição, nas decisões judiciais", bem como uma fração de

30 Entendendo-se "campo jurídico" como o espaço onde seus agentes confrontam-se pelo "monopólio do direito de dizer o direito". BOURDIEU, Pierre. A Força do Direito: elementos para uma sociologia do campo jurídico. Tradução de Fernando Tomaz. In: BOURDIEU, Pierre. O poder simbólico. Rio de Janeiro: Bertrand Brasil, 1989, p. 212. 
TOLEDO, Cláudia Mansini Queda; JÚNIOR, Luiz Carlos de Souza. Análise dos apontamentos críticos ao judicial review. Revista Eletrônica Direito e Política, Programa de Pós-Graduação Stricto Sensu em Ciência Jurídica da UNIVALI, Itajaí, v.11, n.3, $3^{\circ}$ quadrimestre de 2016. Disponível em: www.univali.br/direitoepolitica - ISSN 1980-7791.

arbitrariedade no agrupamento de atos que os precedem e os determinam, evento este ligado às decisões da política que dizem respeito à prisão ${ }^{31}$.

Nos termos do sociólogo francês, o direito tem sua autonomia relativa, pois, por vezes, está a serviço dos dominantes, haja vista que há?

[...] no direito e na jurisprudência um reflexo directo das relações de força existentes, em que se exprimem as determinações econômicas e, em particular, os interesses dos dominantes, ou então, um instrumento de dominação $[\ldots]$.

De facto, a interpretação da lei nunca é o acto solitário de um magistrado ocupado em fundamentar na razão jurídica uma decisão mais ou menos estranha, pelos menos na sua génese, à razão e ao direito, e que agiria como hermeneuta preocupado em produzir uma aplicação fiel da regra, como julga Gadamer, ou que actuaria como lógico agarrado ao rigor dedutivo do seu "método de realização", como queria Motulsky. Com efeito, o conteúdo prático da lei que se revela no veredicto é o resultado de uma luta simbólica entre profissionais dotados de competências técnicas e sociais desiguais, os meios ou recursos jurídicos disponíveis, pela exploração das "regras possíveis", e de os utilizar eficazmente, quer dizer, como armas simbólicas, para fazerem triunfar em sua causa ${ }^{32}$.

A partir deste referencial utilizado para aclarar o debate em torno da autonomia relativa do Direito, considera-se que o efeito jurídico da regra (sua significação real) está determinado pelas relações de força entre os profissionais do campo, além da presença de forças externas (política, jornalística, religiosa etc.) que os influenciam, que determinam as lutas de concorrência que arquitetam uma lógica interna ou mesmo indicam os conflitos de competência.

Portanto, o trabalho de racionalização dos magistrados em uma decisão jurídica, ligada não só às normas puras do direito, mas às atitudes éticas dos agentes,

31 BOURDIEU, Pierre. A Força do Direito: elementos para uma sociologia do campo jurídico. Tradução de Fernando Tomaz. In: BOURDIEU, Pierre. O poder simbólico. Rio de Janeiro: Bertrand Brasil, 1989, p. 223.

32 BOURDIEU, Pierre. A Força do Direito: elementos para uma sociologia do campo jurídico. Tradução de Fernando Tomaz. In: BOURDIEU, Pierre. O poder simbólico. Rio de Janeiro: Bertrand Brasil, 1989, p. 224. 
TOLEDO, Cláudia Mansini Queda; JÚNIOR, Luiz Carlos de Souza. Análise dos apontamentos críticos ao judicial review. Revista Eletrônica Direito e Política, Programa de Pós-Graduação Stricto Sensu em Ciência Jurídica da UNIVALI, Itajaí, v.11, n.3, $3^{\circ}$ quadrimestre de 2016. Disponível em: www.univali.br/direitoepolitica - ISSN 1980-7791.

confere eficácia simbólica à decisão judicial quando, ignorando-se o que há de arbitrário, é reconhecida como legítima.

\section{CONSIDERAÇÕE FINAIS}

Com base no conteúdo exposto, pode-se concluir que as críticas ao judicial review estão vinculadas ao fenômeno da ascensão institucional do Poder Judiciário. Assim, as objeções à revisão judicial são apresentadas no intuito de defender a legitimidade democrática de órgãos eleitos da atuação dos graus de ativismo judicial.

Com isso, é possível enunciar, a partir da primeira objeção intitulada como dificuldade contramajoritária, que os adeptos dessa corrente defendem a ideia de democracia à noção de maioria, pois se filiam à ideia de inadmissibilidade dos órgãos não eleitos invalidarem leis ou atos normativos emanados pelo Poder Legislativo composto por representantes eleitos pelo povo.

No entanto, em que pese a ideia do valor dado às decisões de magistrados não eleitos democraticamente, pode-se perceber, por outro lado, que o controle judicial de constitucionalidade das leis é também um pressuposto basilar de um Estado Democrático de Direito, pois é uma forma de garantir a proteção dos direitos fundamentais e das regras essenciais da própria democracia.

No que concerne à segunda objeção denominada supremacia judicial, as críticas convergem-se para a politização dos tribunais (tendo estes que se preocupar com os julgamentos de casos que interessem às partes litigantes) e à possibilidade de interpretação constitucional para além das vozes das Cortes Supremas (como pelos membros do Poder Legislativo e pelo próprio povo). Neste terreno, que acaba por envolver os limites de separação entre o direito e a política, cabe enunciar que ao julgador/intérprete é praticamente impossível se desvincular de certo papel criativo na concretização do conteúdo previsto na norma, pois elementos volitivos e cognitivos fazem parte da aplicação do direito pelos magistrados e tribunais, inclusive no que tange às normas constitucionais. 
TOLEDO, Cláudia Mansini Queda; JÚNIOR, Luiz Carlos de Souza. Análise dos apontamentos críticos ao judicial review. Revista Eletrônica Direito e Política, Programa de Pós-Graduação Stricto Sensu em Ciência Jurídica da UNIVALI, Itajaí, v.11, n.3, $3^{\circ}$ quadrimestre de 2016. Disponível em: www.univali.br/direitoepolitica - ISSN 1980-7791.

E a Corte Superior encontra-se no topo do sistema, desfrutando de lugar primordial na determinação do sentido e alcance da Carta Magna e das leis, sendo a detentora da última palavra que vinculará os demais Poderes.

Assim, pode-se afirmar que, diante dos posicionamentos críticos ora apresentados, no recorte realizado pelo artigo restam indícios consideráveis de que as objeções ao judicial review são apresentadas com o propósito de defender a legitimidade democrática de órgãos eleitos da atuação dos graus de ativismo judicial. As críticas elencadas buscam assinalar o status autônomo do direito, livre da politização do Judiciário, adequado à vontade popular por meio de seus representantes etc., porém, isso nem sempre é possível, uma vez que, na realidade, a referida autonomia é relativa, haja vista que o Direito está sob influência de outros campos (forças econômicas, políticas, religiosas, jornalísticas etc.) que devem ser considerados a partir das relações de força da sociedade.

\section{REFERÊNCIAS DAS FONTES CITADAS}

BARBOSA, Rui. Atos inconstitucionais. $3^{a}$ ed. - Campinas: Russel Editores, 2010.

BARROSO, Luís Roberto. Constituição, Democracia e Supremacia Judicial: Direito e Política no Brasil Contemporâneo. Revista da Faculdade de Direito- UERJ, v. 2, n. 21, jan./jun. 2012. Disponível em http://www.epublicacoes.uerj.br/index.php/rfduerj/article/view/1794. Acesso em 7 de fevereiro de 2015.

BOURDIEU, Pierre. A Força do Direito: elementos para uma sociologia do campo jurídico. Tradução de Fernando Tomaz. In: BOURDIEU, Pierre. 0 poder simbólico. Rio de Janeiro: Bertrand Brasil, 1989.

BRASIL. Decreto $n^{\circ} 848$, de 11 de outubro de 1890 , art. $9^{\circ}$, parágrafo único, b. Disponível em http://www.planalto.gov.br/ccivil_03/decreto/18511899/d848.htm. Acesso em 5 de fevereiro de 2016.

BICKEL, Alexander. The Least Dangerous Branch. New Haven: Yale University Press, 1963, pp. 16-17. Disponível em http://www.law.uh.edu/faculty/eberman/conlaw/Bickel.pdf. Acesso em 5 de fevereiro de 2016.

BUNCHAFT, Maria Eugenia. Minimalismo Judicial, Constitucionalismo Democrático: uma reflexão sobre os direitos de minorias sexuais da 
TOLEDO, Cláudia Mansini Queda; JÚNIOR, Luiz Carlos de Souza. Análise dos apontamentos críticos ao judicial review. Revista Eletrônica Direito e Política, Programa de Pós-Graduação Stricto Sensu em Ciência Jurídica da UNIVALI, Itajaí, v.11, n.3, 30 quadrimestre de 2016. Disponível em: www.univali.br/direitoepolitica - ISSN 1980-7791.

Jurisprudência da Suprema Corte Norte-Americana. Revista Novos Estudos Jurídicos, vol. 19, n. 1, 2014, Universidade do Vale do Itajaí. Disponível em http://siaiap32.univali.br/seer/index.php/nej/article/view/5545. Acesso em 27 de fevereiro de 2016.

ELY, John Hart. Democracia e Desconfiança - Uma teoria do controle judicial de constitucionalidade, Tradução de Juliana Lemos. São Paulo: Martins Fontes, 2010.

LIJPHART, Arend. Modelos de democracia: desempenho e padrões de governo em 36 países. Rio de Janeiro: Civilização Brasileira, 2003.

MENDES, Gilmar Ferreira; COELHO, Inocêncio Mártires; BRANCO, Paulo Gustavo. Curso de Direito Constitucional. São Paulo: Saraiva, 2007.

ALMEIDA NETO, Manuel Carlos. Antecedentes históricos do controle difuso
de constitucionalidade das http://www.buscalegis.ufsc.br/revistas/files/anexos/31795-36810-1-PB.pdf.

Acesso em 3 de fevereiro de 2016.

OLIVEIRA, Leandro Correa de. O Judicial Review permite um diálogo entre poderes. Consultor Jurídico, 23 de novembro de 2012. Disponível em http://www.conjur.com.br/2012-nov-23/leandro-oliveira-judicial-review-permitedialogo-entre-poderes. Acesso 06 de fevereiro de 2016.

OLIVEIRA, Rafael Machado de. Ativismo judicial no Brasil e a importância da experiência norte-americana em hermenêutica constitucional. Fórvm Nacional da Advocacia Pública Federal. Disponível em http://www.advocaciapublica.com.br/forum/artigos/ativismo-judicial-no-brasil-ea-importancia-da-experiencia-norte-americana-em-hermeneutica-constitucional. Acesso em 15 de setembro de 2016.

PINTO, José Guilherme Bernan Corrêa. Repercussão Geral e Writ of Certiorari. Dissertação (Mestrado em Direito). Pontifícia Universidade Católica do Rio de Janeiro. Rio de Janeiro: 2006. Disponível em http://www.dominiopublico.gov.br/download/teste/arqs/cp077202.pdf. Acesso em 06 de fevereiro de 2106.

ROSENFELD, Michael. Constitutional Adjudication in Europe and United States: paradoxes and contrasts. In: International Journal of Constitutional Law. Oxford University Press and New York University Shool of Law 2004, I-CON, Volume 2, Number 4, $2004 . \quad$ Disponível em http://icon.oxfordjournals.org/content/2/4/633. full.pdf+html?sid =6422b01fbe38-43dc-bd51-72fbd5ba2edb. Acesso em 05 de fevereiro de 2016.

SUSTEIN, Cass R.. Beyond Judicial Minimalism. The Law Scholl The University of Chicago. 2008.2 Deptember 2 em http://www.law.uchicago.edu/files/files/LE432.pdf. Acesso em 27 de fevereiro de 2016. 
TOLEDO, Cláudia Mansini Queda; JÚNIOR, Luiz Carlos de Souza. Análise dos apontamentos críticos ao judicial review. Revista Eletrônica Direito e Política, Programa de Pós-Graduação Stricto Sensu em Ciência Jurídica da UNIVALI, Itajaí, v.11, n.3, $3^{\circ}$ quadrimestre de 2016. Disponível em: www.univali.br/direitoepolitica - ISSN 1980-7791.

SWISHER, Carl Brent. Decisões históricas da Corte Suprema. Rio de Janeiro: Forense, 1962.

WALDRON, Jeremy. A essência da oposição ao judicial review. In: BIGONHA, Antônio Carlos Alpino; MOREIRA, Luiz (Org.). Legitimidade da jurisdição constitucional. Rio de Janeiro: Lumen Juris, 2010.

Submetido em: maio/2016

Aprovado em: julho/2016 